\title{
A DIVERSIDADE DE CULTURAS E A COMPLEXIDADE DO CONCEITO
}

\author{
Maria de Lurdes Mattos Dantas Barbosa ${ }^{3}$
}

\section{RESUMO}

Este artigo é o resultado de investigações e estudos realizados nas aulas da disciplina de Culturas, Saberes e Práticas, do Curso de Mestrado da Universidade de La Empresa, e tem como enfoque principal, a reflexão sobre a diversidade de culturas, a complexidade, multiplicidade, e a falta de consenso em relação ao conceito de cultura. Busca reconhecer a dinâmica, a relação e o diálogo permanente entre a pluralidade cultural e educação, dando ênfase a pratica pedagógica, ao utilizar os conflitos inerentes ao processo na construção e reconstrução do conhecimento científico. Foca também a atenção na questão dos preconceitos, discriminação e cotas nas Universidades brasileiras nas ações afirmativas como procedimento de reparação aos afrodescendentes pelo passado histórico do escravismo no Brasil.

PALAVRAS - CHAVE: Cultura, Educação, Conceito, Complexidade

\section{ABSTRACT}

This article is the result of investigations and studies carried out in the classes of the discipline of Cultures, Knowledge and Practices, of the Master Course of the University of La Empress, and its main focus is the reflection on the diversity of cultures, complexity, multiplicity, and lack of consensus on the concept of culture. It seeks to recognize the dynamics, relationship and permanent dialogue between cultural plurality and education, emphasizing pedagogical practice, using the inherent conflicts of the process in the construction and reconstruction of scientific knowledge. It also focuses on the issue of prejudice, discrimination and quotas in Brazilian Universities in affirmative actions as a procedure to repair Afro-descendants by the historical past of slavery in Brazil.

KEY WORDS: Culture, Education, Concept, Complexity

\footnotetext{
${ }^{3}$ Professora graduada em História pela Universidade estadual do Estado da Bahia - UNEB. Pós-graduada em Metodologia do Ensino de História pelo Instituto Brasileiro de Pós-graduação e Extensão -IBPEX. Mestranda em Ciências da Educação pela Universidade de La Empresa - Uruguai E-mail lurdinhadantas44@yahoo.com
} 


\section{Introdução}

A diversidade de culturas e a multiplicidade de conceitos que ao longo da história foram sendo editados são ainda na contemporaneidade, assunto relevante, haja vista, ser essa temática estudada e analisada em várias áreas do conhecimento científico como, por exemplo, na História, na Antropologia, Economia, na Comunicação e Sociologia, entre outros. Essa última, procura definir e entender a cultura, através do contato social que os indivíduos estabelecem e compartilham na convivência, e em particular no seio da comunidade, revelando assim, a realidade social das pessoas do grupo. Para ela, a cultura é tudo o que se relaciona com a criação humana, e possibilita durante o convívio social, a participação a comunicação e interação, entre muitos outros fatores relevantes considerados pela sociedade normativa como desejáveis, outros, indesejáveis dentro do contexto da diversidade.

$\mathrm{Na}$ educação, a cultura é um requisito imprescindível, como estudo, pesquisa, interpretação, vivência, conhecimento enfim. Os ícones, derivados do desdobramento que dela se origina, tais quais, as funções, diversidade, política cultural, economia da cultura, indústria cultural, cultura nacional, etc., são importantes no contexto, desde quando oportuniza aos sujeitos, construir, debater, discutir conceitos, reconhecer a cultura nas diversas formas de crenças, hábitos, costumes, práticas, e tantos outros fatores, sobretudo, verificar os instrumentos que utilizados na prática cotidiana podem influenciar na cultura.

A cultura é também um relevante fator de desenvolvimento social, onde as atividades sócio educativas diversas são incentivadas e estimuladas, no sentido de apoiar ações de teor cognitivo e terapêutico, e como ferramenta de combate aos problemas sociais, além de outras tantas prerrogativas.

Esse artigo está dividido em três momentos distintos e coerentes entre si, objetivando refletir sobre essa temática. O primeiro momento se relaciona com a complexidade do conceito de cultura, diferença cultural, interpretações e significados. O segundo, mantém o foco da cultura no contexto da educação e a relação entre ambas. O terceiro enfoque diz respeito ao hibridismo cultural e/ou encontro de culturas, preconceitos raciais, sistema de cotas para afro descendentes no Brasil, diversidade cultural.

Portanto, de acordo estudos realizados, a cultura, é uma construção histórica, não o resultado de leis biológicas, nem tampouco físicas, constituída de objetos simbólicos, normas, ideias, valores que criam a realidade social entre aqueles que dela compartilham. Dentro desse contexto, esse 
trabalho acadêmico se propõe a dialogar com autores e chegar a um consenso sobre a relevância dessa temática para a educação.

\section{Conceito de Cultura: complexidade, diferença cultural, interpretações e concepções}

A complexidade do conceito de cultura é uma realidade premente ainda hoje e está sujeito a múltiplas interpretações. Logo, tomando, como exemplo, o pensamento de Edward Burnner Tylor, após leituras diversas e analisado em variados trabalhos acadêmicos, pode-se dizer que o sistema cultural está em permanente processo de mudança e transformações. Nesse interim vale ressaltar que a grande contribuição de Tylor (2009, n.p.), foi sua tentativa de conciliar a evolução da cultura e sua universalidade. Foi o primeiro a abordar os fatos culturais sob um prisma sistemático e geral," Dessa forma, fica evidente que, assim, como a cultura, o mundo contemporâneo considerado Pós-moderno para alguns, globalizado, informatizado, capitalizado, e virtualizado, do século XXI, passa seguramente, por mudanças significativas e inovações paradigmáticas e evolutivas em todas as áreas do conhecimento científico e setores da vida como um todo.

A cultura dentro desse contexto, não foi, e talvez nunca seja definida e interpretada de maneira consensual, o que possibilita esse termo ser usado e/ou utilizado em distintos campos semânticos e em diferentes conotações de acordo a sociedade, à época, a história, e valores, entre outros fatores relevantes para a utilização da expressão e pluralidade de significados conceituais. De acordo com CANEDO, (2009.p.1),

Parte dessa complexa distinção semântica se deve ao próprio desenvolvimento do termo. A palavra cultura vem da raiz semântica colore, que originou o termo em latim, cultura, de significados diversos. [...] Até o século XVI, o termo era geralmente utilizado para se referir a uma ação e a processos, no sentido de ter "cuidado com algo", seja com os animais, ou com o crescimento da colheita, e também para designar o estado de algo que fora cultivado, como uma parcela de terra cultivada. (CANEDO, 2009, n.p.)

O estudo sobre a complexidade do conceito de Cultura nos variados sentidos, interpretações e concepções constituídos ao longo da história, oportuniza referencial teórico importante para se adentrar no cerne do pensamento de autores das distintas áreas das ciências e constatar a diversidade de opiniões, entendimentos e demais fatores que se desdobram do objeto em constante mudança, o termo Cultura. 
Parafraseando Canedo (2009), o referido termo foi sendo consolidado de forma singular e figurada, nas sociedades nacionais e nas interações sociais especificas, especialmente nos meios,artísticos e intelectuais nos séculos XVIII e XIX, conforme fundamenta a autora no seu artigo "Cultura é o quê? Reflexões sobre o Conceito de Cultura e a atuação dos Poderes Públicos", segundo ela, posteriormente, a cultura passa a ser entendida distintamente em países como a França e a Alemanha, respectivamente.

No artigo de Fleury (2002) a cultura é apresentada "[...] como a totalidade acumuladora de padrões culturais de sistemas organizados de símbolos significantes". (GEERTZ, 1989, p.58 apud FLEURY, 2002, n.p.). Refletindo sobre o conceito de cultura para Geertz, compreende-se que o mesmo não está centrado em leis, nem tampouco tem como objetivo busca-las no processo, mas, centra-se na procura de significados e na interpretação destes, o que caracteriza a cultura como ciência interpretativa.

Um fator polêmico dentro desse enfoque é sobre a Cultura Nacional, e aqui vamos discorrer sobre o pensamento de Hall (2003), que apresenta e discute criticamente esse assunto, além de enfatizar o fato de que a lealdade e a identificação - comuns nas sociedades mais tradicionais e/ou pré-modernas dadas a tribo, ao povo e a religião - terem sido transferidas gradualmente nas sociedades ocidentais para a cultura nacional, que ele classifica como distintamente Moderna.

\section{Segundo HALL,}

A formação de uma cultura nacional contribuiu para criar padrões de alfabetização universais, generalizou uma única língua vernácula como o meio dominante de comunicação em toda a nação, criou a cultura homogênea e manteve instituições culturais nacionais, como por exemplo, um sistema da educação nacional. Dessa, e de outras formas, a cultura nacional se tornou uma característica chave da industrialização e um dispositivo da modernidade. (HALL, 2003, p.49-50)

A partir da fala do autor, e através de estudos e pesquisas, pode-se compreender que a cultura nacional, aqui explicitada, procura unificar os sujeitos, independente das especificidades, quer seja de classe, raça ou gênero, além de outras. HALL faz um questionamento persistente: "seria a identidade nacional, uma identidade unificadora desse tipo, uma identidade que anula e subordina a diferença cultural?" (IDEM, p.59), Esugere que "invés de pensar as culturas nacionais como unificadas, deveríamos pensá-las como constituindo um dispositivo discursivo que representa a diferença como unidade ou identidade.". (IDEM, p. 61-62). 
Logo, representá-la como a manifestação da cultura implícita de um único povo, é, na verdade, uma maneira visível de unificá-las. As diferenças culturais são realidades vivenciadas pela sociedade globalizada, e as divergências que, por vezes, ocorrem dentro do mesmo espaço social, é fato comum; assim como a dinâmica no processo de mudanças é também uma atividade constante, haja vista, a cultura não ser estática, mas protagonista de vários contextos inovadores, e do conhecimento adquirido através do convívio social entre os seus membros.

Restrepo, por sua vez, aborda sobre a temática da cultura e da diferença cultural na contemporaneidade. As subalternidades, resistências, tecnologias de governo, mercantilização, capital, entre outros, são no contexto, pontos relevantes para reflexão. Segundo esse autor,

Estamos assistindo a uma época em que a cultura em geral e a diferença cultural em particular, constituem os termos de inteligibilidade e interpelação de um número crescente de pessoas (não só especialistas, funcionários, políticos e ativistas), assim como um campo de uma série de tecnologias de governo e mercantilização de existência. A cultura e a diferença cultural, tem tornado o terreno, desde onde se articulam normalizações e se produzem populações, mas também tem constituído o diagrama de poder desde onde certas subalternidades (as vezes configuradas como tais, pela visibilidade mesma do dispositivo culturalista) estabelecem suas resistências. (RESTREPO, 2012, p.165)

Refletir um pouco mais sobre o pensamento desse autor, no que diz respeito a cultura e a diferença cultural, - que ele considera como "ancora e fonte de operação do capital, não só com a produção de mercadorias e imaginários, mas também, com a apropriação da análise cultural por parte da racionalidade empresarial e de mercado", se faz necessário, pois, corrobora para o testemunho da complexidade que envolve o estudo sobre cultura de maneira geral.

Esse tema é um campo aberto para evoluções interpretativas, desde quando não há consenso, e a amplitude de variáveis e especificidades em áreas especificas do conhecimento cientifico e das sociedades humanas, oportunizam a operacionalidade do conhecimento sobre estudos culturais nas mais variadas formas e concepções.

\section{A Cultura no contexto da Educação}

A educação é um agente de transformação e construção do conhecimento, a ferramenta inovadora, evolutiva e de poder. Dialoga e interaciona com a cultura, estabelecendo relações intrínsecas interdependentes de desenvolvimento nas áreas que Ihes correspondem. Entretanto, Cultura e Educação forma um binômio carregado de embates e conflitos, em meio ao 
multiculturalismo comum no ambiente sociocultural das escolas e universidades. SANTOS afirma que

Cultura é uma construção histórica, seja como concepção, seja como dimensão do processo social. Ou seja, a cultura não é algo natural, não é uma decorrência de leis físicas ou biológicas. Ao contrário, a cultura é um produto coletivo da vida humana. (SANTOS, 1983, p. 45)

Portanto, a cultura no processo da aprendizagem e do ensino, conduz ao reconhecimento da pluralidade cultural. E como produto da ação humana, é carregada de valores, heranças, saberes e tradições, que vão sendo transmitidas entre gerações, ao mesmo tempo em que, inovações múltiplas vão sendo desenvolvidas ao longo do tempo e da história.

$\mathrm{Na}$ educação, pode atuar como ferramenta da prática educativa, numa perspectiva de reconhecimento das outras culturas, levando em consideração a padronização, hegemonização, os conflitos, que comumente envolve o processo de socialização no interior das instituições educacionais.

De acordo com Cárdenas, no artigo, Cultura Institucional: aspectos y estratégias a trabajar,

a instituição não é um sistema acabado, uma vez estabelecido, não é um modelo absoluto, mas que a instituição é um "construir": é uma construção permanente a cargo dos indivíduos que a integram, os atores, entendida assim, no marco de uma racionalidade relativa. (CÁRDENAS, s.a., p. 23)

Dessa forma, os sujeitos que compartilham a educação dentro dos centros educativos - estruturas de caráter e interação social que regulam o comportamento dos educandos, promovem o ensino e a aprendizagem no contexto da diversidade cultural - devem considerar na prática pedagógica, as emoções, os pensamentos, crenças, convicções, diferenças, os valores históricos, psicológicos, como também, as variantes linguísticas, os dialetos, que caracterizam os perfis dos educandos oriundos de culturas singulares e distintas, provenientes das variadas regiões geográficas.

Ainda seguindo a linha de pensamento de Cárdenas "em toda instituição educativa, há conflitos, ente professores, entre professores e alunos, entre alunos, professores e pais de alunos, entre professores e a direção, entre pais, entre setores.". (CÁRDENAS, s.a., p.24).

E aqui, nos referimos basicamente, na competência - capacidade de aplicar conhecimentos, atitudes e habilidades - dos envolvidos no processo educacional em saber utilizar todo o referencial cultural da interculturalidade; usar os conflitos como ferramenta pedagógica no processo da prática educativa para estudo e formação cultural, tendo em vista a conservação dos 
valores, a relação dos mesmos com os aspectos do conhecimento, a educação e as suas teorias e práticas, no cotidiano acadêmico.

Segundo Tejera, "os conflitos são inerentes as organizações, Scharstein aumenta que o conflito é um modo de expressão que fala da organização e de seus integrantes, a organização sempre é um fundo de conflito.". (TEJERA, s.a,p.4).

Logo, dentro das instituições educacionais, percebe-se, através de experiência própria, que não é tarefa fácil - porém necessária para a prática docente - lidar com a heterogeneidade das etnias miscigenadas, otimizar e operacionalizar pedagogicamente as causas conflitantes derivadas do preconceito racial, cultural e outros, que comumente são vivenciadas pelas pessoas no convívio sociocultural do cotidiano escolar.

Assim, fica evidente que a relação entre educação e cultura forma um binômio intrínseco, indissociável, interdependente e complexo, com especificidades peculiares no transcurso do diálogo permanente da construção e reconstrução do conhecimento cientifico.

\section{Hibridismo cultural, preconceitos, diversidade cultural e cotas nas Universidades brasileiras.}

Hibridismo cultural é um assunto que possibilita discutir e contrapor teoricamente levando-se também em conta o empirismo, a relevância e/ou não, do multiculturalismo para o estabelecimento do diálogo entre as culturas, como defende Canclini (2011) e de BHABHA (2010) ao afirmar ser o hibridismo o resultado do embate, ou seja, do choque entre as culturas. Assim, não pode-se dizer, com base não pensamento de BHABHA, que o hibridismo seja um processo de adaptação ou mesmo de ressignificação da cultura, mas se sustenta na tensão decorrente do encontro de culturas. Hall (2003) defende que o hibridismo ocorre no processo, ou melhor, no contexto da diáspora, essa afirmação, se fundamenta nos estudos e pesquisas realizadas por ele, sobre os caribenhos, quando rumaram em direção à Grã-Bretanha.Logo, percebe-se que o conceito de hibridismo, a priori, instituído por Canclini, não é consensual.

Analisando a sociedade cultural brasileira, através dos processos históricos e na experiência cotidiana de 30 anos no exercício do magistério público em Centros Educativos da educação Básica, podemos dizer seguramente, que a convivência entre as culturas que se estabeleceram 
em solo brasileiro, desde o seu "descobrimento" pelos portugueses, até a contemporaneidade, em termos gerais, é de conflito, descriminação e preconceito, com raras exceções.

A cultura indígena, negra, afrodescendente, vive em meio ao desrespeito, lutando cotidianamente pelo respeito aos direitos constitucionais, muitas vezes, relegados e ignorados, até mesmo dentro das instituições educacionais e Universidades. O Brasil é um país miscigenado, sem raça, mestiço, multicultural, onde a pluralidade de culturas originou o povo brasileiro, mas o preconceito racial é uma realidade e o diálogo entre os diferentes, nem sempre é amistoso.

As regiões Norte e Nordeste, por exemplo, na contemporaneidade, vivem hoje, "massacradas", descriminadas, escrachadas, por pessoas das regiões do Sul e Sudeste, que por serem miscigenados por imigrantes europeus mais comumente e terem maior desenvolvimento industrial, maior riqueza e poder aquisitivo entre outros, se consideram superiores e demonstram através da mídia, nas redes sociais e nos embates do cotidiano nas ruas e centros urbanos, nas escolas e centros acadêmicos, o repúdio pela população nordestina, mais negra, mais empobrecida. Essas informações são verdadeiras, vivenciadas, observadas e constatadas ao longo do tempo.

O Brasil possui atualmente, uma população de 207,7 milhões de habitantes, conforme pesquisa recente ${ }^{4}$.

Com uma população grande, diversificada, hibrida e de maioria afro descendente, as desigualdades e o desrespeito às diferenças são fatos corriqueiros no cotidiano do brasileiro e noticiado dentro e fora do país.

No contexto da educação, em todos os níveis e modalidades de ensino, o fazer pedagógico, a prática educativa, as leis, normas, regras, etc., para conscientizar, promover a igualdade social e cultural no âmbito acadêmico, ainda não surtiu efeito satisfatório.

A Constituição Federal de 1988, no art.5 inc.42, considera o racismo como crime inafiançável e imprescritível. E as Diretrizes Curriculares Nacionais para a Educação das Relações ÉtnicoRaciais e para o ensino de História e Cultura Afro-Brasileira e Africana (BRASIL, 2004, p.13), afirma que o termo foi ressignificado pelo Movimento Negro em diversas situações que o utiliza com um sentido político e de valorização do legado deixado pelos africanos. Assim como determina também que

\footnotetext{
${ }^{4}$ Pesquisa divulgada pelo IBGE - Instituto de Geografia e Estatística em seu endereço eletrônico no dia (30/08/2017).
} 
Cabe ao Estado promover e incentivar políticas de reparações, no que cumpre ao disposto na Constituição Federal, ART.205, que assinala o dever do Estado de garantir indistintamente, por meio da educação, iguais direitos para o pleno desenvolvimento de todos e de cada um, enquanto pessoa, cidadão ou profissional. (BRASIL, 2004, p.11)

O sistema de cotas na Educação Superior, foi um acontecimento de muita polêmica na sociedade, haja vista, desagradar aqueles que não gostariam de compartilhar o espaço acadêmico com a classe considerada subalterna, tendo como entrada facilitada, as cotas para afro descendentes.

No ano de 2003, a Universidade do Rio de Janeiro -UERJ - e a Universidade do Norte Fluminense - UENF - reservaram $40 \%$ das vagas para estudantes negros, egressos de escolas públicas. Vale ressaltar que outras Universidades como a Federal de Mato Grosso do Sul - UFMT - a Universidade de Brasília - UnB - e a Universidade do Estado da Bahia - UNEB - também aderiram ao sistema de cotas. Dessa forma, o Ensino Superior gradativamente foi se adequando e se reorganizando para essa nova realidade.

As tensões são relevantes e persistem, pois, o encontro de culturas antagônicas ocasionam animosidades históricas, resquícios da escravidão negra, e a suposta supremacia "branca" que não hesita em demostrar o repúdio pela própria descendência, haja vista, ser o povo brasileiro, uma gente "miscigenada".

Dentro desse contexto, é interessante dizer, após analise com base na pesquisa empírica, que o hibridismo cultural, não só oportuniza o diálogo entre as variadas culturas, isso ocorre de fato, mas também as tensões, os choques, os embates, estão constantemente presentes.

Não cabe aqui generalizações em um país tão vasto, etnicamente plural, de costumes e hábitos singulares; de variados dialetos, variantes linguísticas, vícios de linguagens, vestuários típicos, culinárias próprias e 'aculturadas", musicalidades idem, e tantos outros fatores significativos e bem peculiares para cada região especificamente. Logo, entende-se que a cultura, com a multiplicidade de conceitos, a complexidade, a falta de consenso, a diversidade, e as estratégias, habilidades, atitudes e competências, utilizadas pelos educadores nesse emaranhado "novelo" intrínseco e relacional entre educação e cultura, vai se desenrolando paulatinamente. O debate e as buscas por melhores condições de: igualdade de oportunidades, qualidade e equidade, serão perenes, como permanentes e dinâmicas são as mudanças e inovações nesse mundo globalizado, volátil, multicultural, paradigmático e, sobretudo, histórico e plural. A importância de estudos, investigações e debates no contexto da educação em todos os níveis sobre a temática da "cultura," seus desdobramentos, evolução do conceito e a pluralidade de interpretações, a 
polifonia de vozes sobre a tal, formas e práticas pedagógicas no cotidiano escolar, a ética nas relações étnicas e multiculturais, são fatores primordiais na construção e reconstrução do conhecimento, na era da globalização, na sociedade informatizada, tecnologicamente avançada do século XXI. Entretanto, nem sempre assim acontece, o porquê desse procedimento, merece maior investigação.

\section{Considerações Finais}

Esse trabalho acadêmico centra a sua relevância na oportunidade de se adentrar na questão e cerne do conceito de cultura a sua complexidade, oportuniza uma visão mais ampliada e também diferenciada dos pensamentos e ideias de alguns teóricos e as respectivas interpretações sobre o tema, nos contexto da diversidade cultural e sociocultural.

Devo acrescentar, que na academia, ao longo da graduação e de duas especializações, o estudo sobre cultura, foi superficial, pouca teoria e quase nenhuma prática. Apesar de ser um conteúdo polemico, rico - pelas derivações interpretações e evoluções do termo - ainda permanece um campo a ser explorado no cotidiano em muitas escolas do ensino Básico e Universidades - sem generalizar evidentemente - mas, conforme pesquisa empírica realizada no decorrer dos anos de estudos e vivência docente.

Santos revela que,

Assim, é comum na América Latina, que as discussões sobre a cultura se refiram a uma história de contribuições culturais de múltipla origem as quais tem por polo de integração os processos que são dominantes no mundo Ocidental no que concerne a produção econômica, à organização da sociedade, à estrutura da família, do direito às ideias, concepções e modos de conhecimentos. (SANTOS, s.a., p. 33-34)

O autor chama atenção sobre o cuidado que devemos ter com a tendência de se entender países como o Brasil como uma mistura de traços culturais." É preciso compreender o processo histórico e evolutivo da cultura para poder interpretar as variadas formas da sua manifestação. E , para tanto, se faz necessário maior aprofundamento nos estudos e investigações.

Portanto, há uma vasta gama de sub temas e tópicos interessantes que podem ser analisados, refletidos, criticamente avaliados como, por exemplo, a afirmação de antropólogo Roy Wagner, sobre a "invenção da cultura" e, muitas outras interpretações, mas, muitas vezes, fica-se na margem e ou/ simplesmente no "passe e repasse" simplificado de conteúdos sobre o assunto 
tanto nos cursos de formação de professores, como também nas atividades educativas de quase todos os níveis de modalidades da educação Básica e Superior.

\section{Referências}

BHABHA, Homi K. O Local da Cultura. Belo Horizonte: UFMG,2010.

BRASIL. Constituição da República do Brasil: Senado Federal, 1988.

CANCLINI, Nestor Garcia. Culturas Híbridas - estratégias para entrar e sair da modernidade. 4 ed. São Paulo: UNESP,2011. Acessível em: www.insite.pro.br Acesso em 03/09/2017

CANEDO, Daniele," Cultura é o quê?" -Reflexões sobre o Conceito de Cultura e a atuação dos Poderes Públicos - Encontro de Estudos Multidisciplinares em Cultura, 2009. Acessível: http://www.cult.ufba.br/enecult2009/19353.pdf Acesso em: 08/08/2017

CARDOSO, João Batista. N. 27, 2008. ITINÉRARIOS - Revista de Literatura - Hibridismo Cultural na América Latina LIMA. Acessível em:Seer.fclar.unesp.br /Acesso em:08/08/2017

HAAL, Stuart. A Identidade Cultural na Pós-modernidade/ tradução, Tomaz

Tadeu da Silva - Guaracira Lopez Louro. 8a ed. Rio de Janeiro: DP\&A,2003.

RESTREPO, y Eduardo. Antropogía e Estudios Culturales: disputas e confluências desde la periferia - $1^{\mathrm{a}}$. Ed. Buenos Aires: Siglo Veintiuno Editores

SANTOS, José Luiz. O que é Cultura? 9a ed. $1^{\mathrm{a}}$ ed.1

SOUZA, Leila Lima, ano IX, n.03, março de 2012 -Revista Temática: O Processo de Hibridação Cultural: prós e contras. Acessível em www.usite.pro.br/Acesso em 10/08/2017

TEJERA, A.Taller de Gestión de conflictos y negociación. 